\title{
Yangın Stratejilerinin Oluşturulması İçin İstatistik Veri Türlerinin Türkiye (İstanbul İli Örneğinde) ve Seçilmiş Ülkeler ile Karşılaştırılması
}

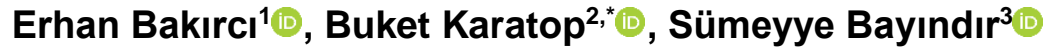 \\ ${ }^{1}$ Istanbul Üniversitesi Cerrahpaşa, Teknik Bilimler MYO, Mülkiyet Koruma ve Güvenlik Bölümü, 34500, İstanbul. \\ ${ }^{2}$ Istanbul Üniversitesi Cerrahpaşa, Teknik Bilimler MYO, Motorlu Araçlar ve Ulaştırma Teknolojileri Bölümü, 34500 , İstanbul.
}

${ }^{3}$ Sakarya Üniversitesi, Mühendislik Fakültesi, Endüstri Mühendisliği Bölümü, 54050, Sakarya.

\section{Özet}

Doğal ve insan kaynaklı afetler sonrasında meydana gelen yangınlar ve yarattı̆̆ kayıpların toplum üzerinde travmatik sonuçlar yarattığ bilinmektedir. Afetlerin yaratacağg zararların en az olmasl, risklerin önceden belirlenmesine ve böylece afet sonuçlarının yönetilebilir olmasına bağlıdır. Afetler ve özellikle yangın afetlerinin toplum üzerinde oluşturduğu maddi manevi kayıplar ile sosyokültürel travmaların yanında eko sistemdeki müthiş etkileri her gün biraz daha hissedilmektedir. Bundan dolayı özellikle yangın güvenliği konusunda toplumsal bilinci yüksek, teknoloji üretip satan veya bu konuda standartlarl oluşturan ülkelerde yangin istatistiklerinin stratejilerini belirlemeye yardımcı olacak nitelikte tutulduğu ve kullanıldı̆̆g söylenebilir. Bu güvenlikli iliskiler zincirinin güçlü olması ögrenen sistemlerin kurulması ile mümkündür. Tüm unsurların ölçülebilir-değerlendirilebilir ve ders alınıp geliştirilebilir veri sisteminin oluşturulmast ve kurulmasında temel faktör sağlam, bilimsel ve hedefe dönük istatistik veri havuzu kurulması ve farkındalık oluşturulmasıdır. Bu çalışmada, 2008 ve 2018 yılları arasında İstanbul'da meydana gelen yangınlara ait istatistikler ile $A B D$, Çin ve AB ülkelerinin yangın istatistikleri karşılaştırllmıştır. Karşılaştırılan ülkelerle Türkiye'de İstanbul ili özelinde tutulan yangın istatistikleri arasındaki veri tipleri incelenmis bu çerçevede tespit edilen farklıklar belirlenmistir. Böylece tutulan verilerin bilimsel çalışmalar ve önleyici yaklaşımla bu konuda stratejiler oluşturmaya elverişli olup olmadĭğ tartışılmış ve iyileștirilmesi hususunda öneriler sunulmuştur.

\section{$\underline{\text { Anahtar Sözcükler }}$}

İstatistik, Yangın İstatistik Verileri, Strateji

\section{Comparing Types of Statistical Data Between Turkey (the Case Study of Istanbul) and Selected Countries for Creating Fire Strategies}

\begin{abstract}
Fires caused by natural factors or man-made and the losses they cause are known to have traumatic consequences for the society. The risk of disasters can be minimized when they are determined in advance and the results of the disasters become manageable. In addition to material and moral losses and socio-cultural traumas caused by disasters, especially fire disasters, the effects on the eco-system are felt more and more every day. Therefore, it can be said that fire statistics are kept and used to determine the strategies of fire statistics, especially in the countries that have high standards of social security and are technologically advanced. The strength of this chain of secure relations is possible with the establishment of learning systems. The basic factor in the creation and establishment of measurable-evaluable and taken lessons from lived data systems is the establishment of a robust, scientific and objective statistical data pool and with awareness raising. In this study, Istanbul Fire Brigade converted fires that occurred in Istanbul between 2008 and 2018 into statistical data. These statistics were compared with the fire statistics of the USA, China and EU countries. The largest and most comprehensive fire statistics database in our country is represented by the Istanbul Province Fire Statistics. Compared to the fire statistics of other countries, it was determined that there were differences in the statistical data classification and evaluation of these data. Thus, it is discussed whether the data held are suitable for creating strategies in this area with scientific studies and preventive approaches, and suggestions for improvement are presented.
\end{abstract}

$\underline{\text { Keywords }}$

Statistic, Fire Statistics Data, Strategy

\section{Giriş}

Doğal ve insan kaynaklı afetlerin sonrasında meydana gelen yangınlar ve yarattığı can-mal kayıplarının toplum üzerinde yarattığı son derece travmatik sonuçları bilinmektedir. İnsanların yaşam kaliteleri ve standartlarının sürdürülebilir olması istenci şehirleşme ve toplu yaşamı zorunlu hale getirmektedir. 
$\mathrm{Bu}$ durumda afetler ve yaratacağı olumsuz sonuçlarına karşı şehirleşme, şehir alt ve üst yapı elemanlarının, yüksek yapıların, yüksek teknik ve teknolojinin kullanıldığı üretim ve depolama alanlarının her durumda hizmet verebilir olması günümüzün afet yönetim stratejilerinin belirlenmesinde önem arz etmektedir.

İnsan veya doğal kaynaklı afetlerin yaratacağı zararların en az olması, risklerin önceden belirlenmesine ve böylece afet sonuçlarının yönetilebilir olmasına bağlıdır. Afetler ve yaratacağı zararların önceden bilinir olması afete süratle müdahale edecek sistem/araç-gereç ve mekanizmaların oluşturulması ve geliştirilmesi ile mümkündür. Özellikle yangın gibi insan kaynaklı afetlerde risklerin önceden bilinir olması bu risklere karşı insanların farkındalığını, risklerin tespitine dönük teknik ve teknolojik ekip-ekipmanın kullanılmasını ve daha ileri teknik ve teknolojik sistemlerin geliştirilmesinde son derece önemlidir.

Bu çalışmanın amacı; Türkiye'de İstanbul İli örneği üzerinden tutulan yangın istatistiklerinin kapsamı ve derinliğinin ABD, Çin ve AB ülkelerinin yangın istatistikleri ile karşılaştırılması, Türkiye genelinde İstanbul İli özelinde tutulan verilerin bilimsel çalışmalar ve önleyici yaklaşımla bu konuda stratejiler oluşturmaya elverişli olup olmadığının belirlenmesi ve yangın güvenliği stratejileri oluşturmada öneriler sunulmasıdır. Karşılaştırma verileri için seçilen ülkeler yangın güvenliği konusunda toplumsal bilinci yüksek veya teknoloji üretip satan veya bu konuda standartları oluşturan ülkelerdir. Aynı zamanda üç farklı kıtadan ülkeler seçilmiştir.

\section{Yangın ve İstatistik}

Yangın, genel anlamda, doğal ortamda bulunan kendiliğinden yanabilen maddeler ile hava arasında kontrol edilemeyen ekzotermik yani dışarıya doğru ısıveren kimyasal reaksiyon olarak ortaya çıkan bir tehlikedir. Teknolojinin gelişimi ile insanların günlük hayatları kolaylaşırken, yaşam alanı farklı özellikler içeren organik maddelerle zenginleşmiş ve bu durum yangına neden olabilecek parlayıcı ve yanıcı madde sayısında ciddi artışa neden olmuştur. Özellikle kentsel alanlarda çok katlı yapılaşmaların benimsenmesi ile yangın kavramı can ve mal güvenliğinin sağlanmasında çok önemli bir sorun haline gelmiştir (Üstündağ ve Boyraz 2008).

İstatistik biliminin birçok tanımı olmakla birlikte en çok kabul gören iki tanım; tekil ve çoğul istatistik tanımlarıdır. Tekil olarak istatistik, "sayısal gerçeklerin toplanması, düzene konulması ve yorumu ile uğraşan bir metodudur" (Çil 2008). Tanımı daha da açmak gerekirse, "belirli bir amaç için veri toplama, verileri tablolar ve grafiklerle özetleme, sonuçları yorumlama, sonuçlara güven derecesini açıklama, örneklemden elde edilen sonuçları genelleme, örneklemler ya da özellikler arasındaki ilgileri araştırma, çeşitli konularda deney düzenleme ve gözlem yapma ilkelerini kapsayan ve tüm bilim dallarına yardımcı olan yöntemleri içeren bir bilim dalıdır" (Şanslı 2008). Çoğul olarak istatistik ise "sistemli bir şekilde toplanan sayısal gerçekleri ifade etmektedir (Çil 2008; Şanslı 2008). Belli bir olayın gözlenmesiyle onun hakkında genel bilgi ve yorumda kullanılan tüm metotları ifade eden bu ikinci anlamına istatistik metodu adı verilmektedir (Dilek 1999).

Özkan (2002)'1n bildirdiğine göre; Türkiye’de 1927 y1lında “Devlet İstatistik Umum Müdürlüğü” olarak kurulan ve 1963 yılında "Devlet İstatistik Enstitüsü” şeklinde teşkilatlanan kurumun, planlı dönemine girildikten sonra istatistiğe duyulan ihtiyacın büyüdüğünün ve öneminin arttı̆̆ı görülmesine rağmen yangın verilerinin tutulmasına ise yeterli önem verilmemiştir (Bekem vd. 2011). Bu da Türkiye'nin yangın istatistiklerini değerlendirmesine, etkin ve etkili bir şekilde analiz etmesine olanak tanımamıştır.

Yangın istatistik analizinin ve sonuçlarının değerlendirilmesinin yangın riski yönetiminde karar verme konusunda yol gösterici olacağı açıktır. Yangın istatistikleri, temel veri yığını ile birlikte yangın bilimi araştırmalarını ve uygulamasını sağlamaktadır. Bu yüzden yangın istatistikleri ve yangın istatistiklerine dair analiz büyük önem taşımaktadır (Wang vd. 2005).

Yangınlarda her yıl çok fazla insan ölmekte veya yaralanmakta bu da çok büyük maddi kayıplara neden olmaktadır. Gelişen teknoloji, sanayileşme ve enerji tüketiminin yaygınlaşması, nüfusun giderek büyümesi yangın riskinin ve buna bağlı olarak yangın afetinin maddi ve manevi zararlarının artışına sebep olmaktadır (Bekem vd. 2011).

\section{Seçilmiş Ülkelerde Yangın İstatistikleri}

AB ülkelerinin ulusal yangın istatistiklerini tutmak için Avrupa Yangın Veri Tabanı olarak bir sistem geliştirmiştir ve bu veri tabanında tarihsel yangın verilerinin dönüşüm sonuçları, veri tabanındaki her ülke için detaylandırılmıştır. Bu verilerin sınıflandırılması konusu ele alınmış ve 22 AB ülkesinin kendi ulusal yangın sınıflandırmasına karşılık gelen standart sınıfa dönüştürme çalışması yapılmıştır (Camia vd. 2013). Burada fark edilmesi gereken çoğu ülkenin 1980 yılları civarında ve hatta daha erken yıllarda veri tutmaya başlamış olmasıdır. Avrupa yangın veri tabanı Türkiye'den 2005 yılından sonra verileri sistemine dahil etmeye başlamıştır. Buradan görülmektedir ki; Türkiye'nin yangın istatistiklerini tutma konusunda diğer ülkelere göre geri planda kaldığı söylenebilir.

Çin, yaklaşık 1,3 milyar nüfuslu gelişmekte olan bir ülkedir. Reform politikası ve dünyaya açılmasından bu yana büyük değişiklikler ve önemli kazanımlar elde ettiği görülmektedir. Bununla birlikte, Çin, yangın olayları riski de dâhil olmak üzere, dünyadaki diğer ülkelerle birçok sorunu paylaşmaktadır. Çin'de son yıllarda artan yangın felaketleri sayısı, ülke çapında ve hatta dünya çapında dikkat çekmektedir (Wang vd. 2005). 
Wang vd. (2005), Çin'in Yangın İstatistikleri Analizi (Analysis of Fire Statistics of China) çalışmasında yangın frekans ve yangın kayıplarını incelemiş, bu analizi yapabilmek için yangın olaylarının ve yangın direkt kayıplarının sayısı, yaralanma sayısı, yangının ekonomik büyümeye etkisini gayri safi milli hasıla verileri ele alınmıştır. Bunun sonucunda farklı bina kategorilerine göre yangın frekansı belirlenmiş, istatistiksel ve regresyon analizleriyle Çin için sosyal risk kriterleri oluşturulmuştur.

Kobayashi (1984),“Japonya'da deprem sonrası yangınlar ile ilgili makalesinde; Japonya'da yangın sayısının fazla olması mevcut evlerin ahşap olması ile ilişkilendirilmiştir. Deprem sonrası meydana gelen yangınların incelendiği bir çalışmada, yangın çıkma oranının yıkılan binalarla değil de deprem şiddeti ile alakalı olarak analiz edilmesi gerektiğinin daha doğru olduğu tespit edilmiştir. Şiddeti 6.0 ve daha az olan depremler sonucu çıkan yangınların toplam yangınlara oranının 0.0002 geçmediği, bunların 0.00015 genel yangın, 0.00005 kimyasal yangınlar olduğu görülmektedir. Deprem şiddeti 7.0 olduğunda yangın çıkma ihtimalinin daha yüksek olduğu belirlenmiştir. Bu bağlamda Japonya'da şiddetli depremler sonrasında birçok yangın çıktığı görülmüştür (Koraltürk 2000).

ABD için yapılan yangın verilerinin raporlama formlarında incelendiğinde (FEMA 2015);yangında yaralanan, ölen sivil insan ve itfaiye elamanı, yangının nerede nasıl çıktığı, binayı yapıyı tanıma, insanın ruh hali, yaralanmasına sebep olacak nedenler, hangi departmanın yangın bölgesine gittiği, yangının haber veriliş anı, varış anı gibi detaylı veriler tutulmakta ve sonradan hata ya da eksik olması durumunda raporlar tekrar düzeltilmekte ya da iptal edilmektedir.

NFPA (National Fire Protection Associaton-Ulusal Yangından Korunma Kurumu), 1977'den bu yana ABD'nin yıllık yangın deneyimini ölçmek için kamu itfaiyesini araştırmış, ABD yangın departmanlarının bu araştırması NFPA'nın yerel itfaiye teşkilatlarının katıldığı yangınların sayısı ve bu olaylarda meydana gelen ölümler, yaralanmalar ve maddi kayıplar ile ölçülen ulusal yangın sorunu tahminlerini yapmalarını sağlamıştır. Bu rapor, 2016 yılındaki ABD yangın davası için yangın departmanlarının NFPA araştırmasına dayanan temel bulguları özetlemekte ve 1977'den 2016'ya kadar yangın kaybı eğilimleri sunulmaktadır. Bu yangın verilerini kullanarak örnek seçimi, bilgi toplama ve tahmin metodolojisi kullanılarak yangın sonucu meydana gelen sonuçlar elde edilmiştir (Haynes 2017).

Uluslararası Yangın ve Kurtarma Hizmetleri Birliği (CTIF-Comité Technique International de prevention et d'extinction de Feu) Yangın İstatistikleri Merkezi (CFS-Center of Fire Statistics), birçok CTIF ülkesinin yangın istatistiklerini ve 2015 için büyük şehirleri ve 2011-2015 eğilimlerini içeren son raporunu yayınlamıştır. Bu raporda yangınlar, yangınlar nedeniyle meydana gelen ölümler, yaralanmalar ve yangınlar ile ilgili itfaiyecilerdeki ölüm ve yaralanmaların sayıları ve oranları hakkında istatistiklere yer almaktadır. Raporda ayrıca, yangın olayı dışı acil müdahale sayıları, büyük bir olay türü ve itfaiyeciler, itfaiye cihazları ve istasyonların sayıları ve oranları hakkında istatistikler de yer almaktadır. 2015 yılı yangın ve kayıp istatistikleri, 31 ülkeden ve dünyadaki 35 şehirden elde edilen verilere dayanmaktadır. 2011-2015 döneminde yangın ve kayıplara ilişkin veriler, 2011-2015 döneminde beş yıldan bir veya daha fazlasına veri sağlayan 43 ülkeden sağlanmıştır (Brushlinsky vd. 2017). Bu ülkeler arasında Türkiye'nin verisine rastlanmamaktadır. Bunun nedeninin Türkiye'nin yangın istatistik verilerini sağlıklı tutmaması ve yangın istatistiklerine daha yeni yeni önem vererek veri ambarları tutması gerektiği düşünülmektedir.

Birleşmiş Milletler Avrupa Ekonomik Komisyonu (UNECE- United Nations Economic Commissionfor Europe) Avrupa için yıllık yangın ölüm sayısının on binlerce olduğunu bildirmekte ve bu artışı en aza indirmenin en etkili yolunun tüketici eğitimi ile birlikte yangın önleme olduğu belirtilmektedir. Bu çabaları koordine etmek için devletin yangın istatistiklerini ve analizlerini toplamak ve ulusal bir yangın güvenliği stratejisi geliştirmek gibi acil eylemlere ihtiyaç duyulduğunu raporda belirtmiştir (GAIN 2009).

\section{4. İstanbul Yangın İstatistikleri}

Ülkemiz genelinde sanayi ve insan yoğunluğu, alt yap-üst yapı etkinliği açısından Marmara Bölgesi stratejik öneme sahiptir. Tüm bu faktörler için stratejik bir yerleşim olmanın ötesinde dünya mirası ve kültürel hazinemiz olan ve ülke nüfusunun dörtte birini temsil eden İstanbul ili bu açından büyük önem taşımaktadır. Bu özellikleri itibarıyla ülkemiz genelinde en gelişmiş itfaiye teşkilatının İstanbul İlinde bulunduğu ve yangın istatistiklerinin belirli bir düzende tutulduğu görülmektedir.

Bu çalışmada İstanbul İtfaiye İstatistikleri 2008-2012 ve 2013-2018yılları için beşer yıllık iki dönemde veriler ele alınarak incelenmiştir. Yangınların istatistiki analizi yapılmamış, çalışmanın amacı gereği sadece yangın istatistiklerini tutma çeşitliliği ve bu verilerden yangın risklerini azaltma stratejilerini belirlemeye yönelik olup olmadığı üzerine odaklanılmıştır. İstanbul Büyükşehir Belediyesi İtfaiye Daire Başkanlığı'nın yayınladığı rapor incelenmiştir (İBB İtfaiye Daire Başkanlığı 2018). Rapordaki veri çeşitliği incelendiğinde (Tablo 1) yangınların yapısal olan ve yapısal olmayan yangınlar olarak iki başlıkta toplandığı; yapısal yangınların dört alt başlıkta (konut, fabrika, diğer bina, araç), yapısal olmayanlar ise üç başlık (ot, çöp, orman-fundalık) altında tutulduğu görülmektedir. Tablo 1'de veri çeşitliliğini göstermek amaciyla sadece 2013-2018 yılları arasındaki veriler sunulmuştur. 
Tablo 1: Yangınlar (2013-2018)

\begin{tabular}{|c|c|c|c|c|c|c|c|c|c|c|}
\hline \multicolumn{11}{|c|}{ Yanginlar (2013-2018) } \\
\hline \multirow{3}{*}{ YIL } & \multicolumn{10}{|c|}{ YANGIN (SAYI) } \\
\hline & \multicolumn{5}{|c|}{ YAPISAL YANGINLAR } & \multicolumn{4}{|c|}{ YAPISAL OLMAYAN YANGINLAR } & \multirow[t]{2}{*}{$\begin{array}{c}\text { GENEL } \\
\text { TOPLAM }\end{array}$} \\
\hline & Konut & Fabrika & $\begin{array}{c}\text { Diğer } \\
\text { Bina }\end{array}$ & Araç & TOPLAM & Ot & Çöp & $\begin{array}{c}\text { Orman } \\
\text { Fundalık }\end{array}$ & TOPLAM & \\
\hline 2013 & 4.902 & 159 & 7.853 & 1.601 & 14.515 & 7.969 & 5.099 & 134 & 13.202 & 27.717 \\
\hline 2014 & 5.261 & 123 & 7.869 & 1.689 & 14.942 & 3.008 & 4.830 & 68 & 7.906 & 22.848 \\
\hline 2015 & 5.869 & 157 & 8.957 & 1.903 & 16.886 & 4.596 & 5.212 & 284 & 10.092 & 26.978 \\
\hline 2016 & 5.910 & 153 & 8.887 & 1.940 & 16.890 & 6.110 & 5.430 & 156 & 11.696 & 28.586 \\
\hline 2017 & 5.762 & 166 & 9.224 & 1.781 & 16.933 & 3.338 & 4.685 & 117 & 8.140 & 25.073 \\
\hline 2017 Ocak - Şubat & 1.200 & 31 & 1.719 & 263 & 3.213 & 42 & 648 & 9 & 699 & 3.912 \\
\hline 2018 Ocak - Şubat & 999 & 22 & 1.411 & 250 & 2.682 & 27 & 598 & 4 & 629 & 3.311 \\
\hline
\end{tabular}

Tablo 1 de görülen veriler derinlemesine çeşitlendirilmediği zaman esaslı verilerin tutulduğu ve incelendiği görülmektedir (Tablo 2 ve Tablo 3). Şöyle ki, yapısal ve yapısal olmayan yangın türleri aylara göre çeşitlendirilmiş (Tablo 2) aynı yangın türleri saate göre de tutulmuştur (Tablo 3). Çalışmada yangın türleri üzerinde durulduğu için Tablo 2 'de sadece 6 aylık rakamlar verilmiştir.

Tablo 2: Aylara göre yangınların dağıımı

\begin{tabular}{|c|c|c|c|c|c|c|c|c|c|c|c|c|c|c|c|c|c|}
\hline \multicolumn{18}{|c|}{ Aylara Göre Yangınların Dağılımı } \\
\hline \multicolumn{16}{|c|}{ Yangınlar } & \multirow{3}{*}{\multicolumn{2}{|c|}{ TOPLAM }} \\
\hline \multirow{3}{*}{\multicolumn{2}{|c|}{$Y l l$}} & \multicolumn{8}{|c|}{ Yapısal Yangınlar } & \multicolumn{6}{|c|}{ Yapisal Olmayan Yangınlar } & & \\
\hline & & \multicolumn{2}{|c|}{ Konut } & \multicolumn{2}{|c|}{ Fabrika } & \multicolumn{2}{|c|}{ Diğer Bina } & \multicolumn{2}{|c|}{ Araç } & \multicolumn{2}{|c|}{ Ot } & \multicolumn{2}{|c|}{ Çöp } & \multicolumn{2}{|c|}{ Orman Fundalık } & & \\
\hline & & Sayı & Yüzde & Sayı & Yüzde & Sayı & Yüzde & Sayı & Yüzde & Sayı & Yüzde & Sayı & Yüzde & Sayı & Yüzde & Sayı & Yüzde \\
\hline \multirow{2}{*}{ క్ర } & 2017 & 684 & $2,70 \%$ & 15 & $0,10 \%$ & 928 & $3,70 \%$ & 162 & $0,60 \%$ & 4 & $0,30 \%$ & 282 & $1,10 \%$ & 1 & $0,00 \%$ & 2076 & $8,5 \%$ \\
\hline & 2018 & 493 & $14,90 \%$ & 11 & $0,30 \%$ & 791 & $23,90 \%$ & 136 & $4,10 \%$ & 9 & $0,20 \%$ & 304 & $9,20 \%$ & 0 & $0,00 \%$ & 1744 & $52,6 \%$ \\
\hline \multirow{2}{*}{ 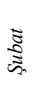 } & 2017 & 516 & $2,10 \%$ & 16 & $0,10 \%$ & 791 & $3,20 \%$ & 101 & $0,40 \%$ & 38 & $0,50 \%$ & 366 & $1,50 \%$ & 8 & $0,00 \%$ & 1836 & $7,8 \%$ \\
\hline & 2018 & 506 & $15,30 \%$ & 11 & $0,30 \%$ & 620 & $18,70 \%$ & 114 & $3,40 \%$ & 18 & $0,30 \%$ & 294 & $8,90 \%$ & 4 & $0,10 \%$ & 1567 & $47,0 \%$ \\
\hline \multirow{2}{*}{$\bar{z}$} & 2017 & 535 & $2,10 \%$ & 11 & $0,20 \%$ & 743 & $3,00 \%$ & 140 & $0,60 \%$ & 87 & $0,30 \%$ & 430 & $1,70 \%$ & 12 & $0,00 \%$ & 1958 & $7,9 \%$ \\
\hline & 2018 & & $0,0 \%$ & & $0,0 \%$ & & $0,0 \%$ & & $0,0 \%$ & & $0,0 \%$ & & $0,0 \%$ & & $0,0 \%$ & 0 & $0,0 \%$ \\
\hline \multirow{2}{*}{$\begin{array}{l}\tilde{y} \\
z \\
z\end{array}$} & 2017 & 535 & $2,10 \%$ & 19 & $0,10 \%$ & 690 & $2,80 \%$ & 168 & $0,70 \%$ & 100 & $0,40 \%$ & 469 & $1,90 \%$ & 26 & $0,10 \%$ & 2007 & $8,1 \%$ \\
\hline & 2018 & 369 & $11,1 \%$ & 7 & $0,2 \%$ & 551 & $16,6 \%$ & 76 & $2,3 \%$ & 8 & $0,2 \%$ & 275 & $8,3 \%$ & 1 & $0,0 \%$ & 1287 & $38,7 \%$ \\
\hline \multirow{2}{*}{ है } & 2017 & 426 & $1,70 \%$ & 12 & $0,00 \%$ & 665 & $2,70 \%$ & 154 & $0,60 \%$ & 118 & $0,50 \%$ & 426 & $1,70 \%$ & 6 & $0,10 \%$ & 1807 & $7,3 \%$ \\
\hline & 2018 & & $0,0 \%$ & & $0,0 \%$ & & $0,0 \%$ & & $0,0 \%$ & & $0,0 \%$ & & $0,0 \%$ & & $0,0 \%$ & 0 & $0,0 \%$ \\
\hline \multirow{2}{*}{$\begin{array}{l}\Xi \\
\mathbb{E} \\
\mathbb{Z}\end{array}$} & 2017 & 423 & $1,70 \%$ & 16 & $0,10 \%$ & 638 & $2,50 \%$ & 159 & $0,60 \%$ & 613 & $2,40 \%$ & 411 & $1,60 \%$ & 3 & $0,00 \%$ & 2263 & $8,9 \%$ \\
\hline & 2018 & & $0,0 \%$ & & $0,0 \%$ & & $0,0 \%$ & & $0,0 \%$ & & $0,0 \%$ & & $0,0 \%$ & & $0,0 \%$ & 0 & $0,0 \%$ \\
\hline
\end{tabular}


Tablo 3: Saatlere göre yangınların dağılımı

\begin{tabular}{|c|c|c|c|c|c|c|c|c|c|c|c|c|c|c|c|c|c|}
\hline \multicolumn{18}{|c|}{ Saatlere göre yangınların dă̆ılımı } \\
\hline \multicolumn{16}{|c|}{ Yanginlar } & \multirow{2}{*}{\multicolumn{2}{|c|}{ TOPLAM }} \\
\hline \multirow{3}{*}{\multicolumn{2}{|c|}{ Saat / Yal }} & \multicolumn{8}{|c|}{ Yapısal Yangınlar } & \multicolumn{6}{|c|}{ Yapısal Olmayan Yangınlar } & & \\
\hline & & \multicolumn{2}{|c|}{ Konut } & \multicolumn{2}{|c|}{ Fabrika } & \multicolumn{2}{|c|}{ Diğer Bina } & \multicolumn{2}{|c|}{ Araç } & \multicolumn{2}{|c|}{ Ot } & \multicolumn{2}{|c|}{ Çöp } & \multicolumn{2}{|c|}{$\begin{array}{l}\text { Orman } \\
\text { Fundalık }\end{array}$} & & \\
\hline & & $\sum_{\infty}^{\infty}$ & 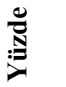 & हై & 芯 & స్స & 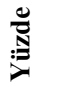 & हై & 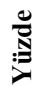 & 胥 & 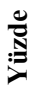 & స్ & 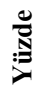 & 窇 & $\underset{\Sigma}{\mathbb{N}}$ & స్లై & $\underset{\mathbb{Z}}{\mathbb{Z}}$ \\
\hline \multirow{2}{*}{$\begin{array}{l}00.00- \\
05: 59\end{array}$} & 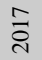 & 155 & 4,0 & 6 & 0,2 & 251 & 6,4 & 49 & 1,3 & 2 & 0,1 & 104 & 2,7 & 0 & 0,0 & 567 & 14,7 \\
\hline & $\stackrel{\text { ¿ }}{\stackrel{4}{*}}$ & 111 & 3,4 & 3 & 0,1 & 208 & 6,3 & 59 & 1,8 & 1 & 0,0 & 83 & 2,5 & 1 & 0,0 & 466 & 14,1 \\
\hline \multirow{2}{*}{$\begin{array}{c}06: 00- \\
11: 59\end{array}$} & $\overline{\vec{n}}$ & 203 & 5,2 & 7 & 0,2 & 298 & 7,6 & 46 & 1,2 & 3 & 0,1 & 95 & 2,4 & 0 & 0,0 & 652 & 16,7 \\
\hline & $\stackrel{\infty}{\stackrel{\sim}{\sim}}$ & 155 & 4,7 & 1 & 0,0 & 246 & 7,4 & 51 & 1,5 & 2 & 10 & 72 & 2,2 & 0 & 0,0 & 527 & 25,8 \\
\hline \multirow{2}{*}{$\begin{array}{c}12: 00- \\
17: 59\end{array}$} & $\overline{\vec{i}}$ & 417 & 10,7 & 9 & 0,2 & 479 & 12,2 & 69 & 1,8 & 27 & 0,7 & 156 & 4,0 & 6 & 0,2 & 1163 & 29,8 \\
\hline & $\stackrel{\infty}{\stackrel{i}{\sim}}$ & 364 & 11,0 & 11 & 0,3 & 406 & 12,3 & 64 & 1,9 & 16 & 0,5 & 168 & 5,1 & 2 & 0,1 & 1031 & 31,2 \\
\hline \multirow{2}{*}{$\begin{array}{c}18: 00- \\
23: 39\end{array}$} & $\widehat{\overrightarrow{\mathrm{i}}}$ & 425 & 10,9 & 9 & 0,2 & 691 & 17,7 & 99 & 2,5 & 10 & 0,3 & 293 & 7,5 & 3 & 0,1 & 1530 & 39,2 \\
\hline & $\stackrel{\infty}{\stackrel{\sim}{\sim}}$ & 369 & 11,1 & 7 & 0,2 & 551 & 16,6 & 76 & 2,3 & 8 & 0,2 & 275 & 8,3 & 1 & 0,0 & 1287 & 38,7 \\
\hline
\end{tabular}

Aynı zamanda tutulan istatistiklerin kapsam ve derinliği itibarıyla yangın güvenliği kapsamında ülke stratejisi oluşturma amacına çok da uygun ve yeterli kapsamda olmadığı söylenebilir. Örneğin konutların tipi, malzemesi, yaşı ve benzeri özellikler bulunmamaktadır. Benzer şekilde diğer bina olarak çok geniş bırakılan bir alanın daha daraltılması geleceğe yönelik tedbir almakta ve karar vermede uzmanlara ve araştırmacılara daha etkili ve verimli analizler yapmalarına yardımcı olacağı söylenebilir.

Bunlara ek olarak yangınlar sınıflandırılmadan genel olarak varış süreleri (Tablo 4) ve yangın nedenleri (Tablo 5) de tutulmaktadır.

Tablo 4: Ortalama varış süreleri.

\begin{tabular}{|c|c|c|c|c|c|c|c|c|c|c|c|}
\hline \multicolumn{12}{|c|}{ Ortalama Varış Süreleri (Dakika: Saniye) (2013-2018) } \\
\hline \multirow[b]{3}{*}{$\begin{array}{c}\text { Ortalama } \\
\text { Varış } \\
\text { Süreleri }\end{array}$} & \multicolumn{11}{|c|}{ YIL } \\
\hline & \multirow[b]{2}{*}{$\stackrel{m}{\bar{\sim}}$} & \multirow[b]{2}{*}{ 离 } & \multirow[b]{2}{*}{$\stackrel{n}{\frac{1}{3}}$} & \multirow[b]{2}{*}{ 욱 } & \multirow[b]{2}{*}{ 혹 } & \multirow{2}{*}{ 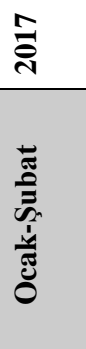 } & \multirow{2}{*}{ 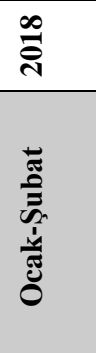 } & \multicolumn{2}{|c|}{ Sayısal Değişim } & \multicolumn{2}{|c|}{ Oransal Değişim } \\
\hline & & & & & & & & 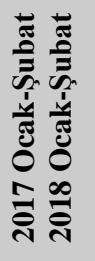 & 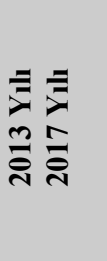 & 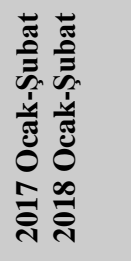 & 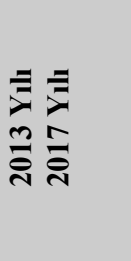 \\
\hline $\begin{array}{r}\text { Yangınların } \\
\text { ortalaması }\end{array}$ & 06:00 & 05:49 & $05: 46$ & 05:46 & $05: 28$ & 05:39 & $05: 23$ & $00: 16$ & $00: 32$ & $-7,72 \% \downarrow$ & $-8,89 \% \downarrow$ \\
\hline
\end{tabular}

Yangın nedenleri; Elektrik kontağı, sigara, kıvılcım sıçraması, baca, kasıt, elektrikli ev aletleri, diğer, kızışma (yüksek ısı ile), tespit edilemedi, çocukların ateşle oynaması, parlama (yanıcı sıvı, yemek parlaması vb.) olarak sınıflandırılmıştır. 
Tablo 5: Istanbul ili yangın nedenleri $(2013-2018)$

\begin{tabular}{|c|c|c|c|c|c|c|c|c|c|c|c|c|}
\hline \multicolumn{13}{|c|}{ YIL } \\
\hline \multirow[t]{2}{*}{$K A Y N A K$} & \multicolumn{2}{|c|}{2013} & \multicolumn{2}{|c|}{2014} & \multicolumn{2}{|c|}{2015} & \multicolumn{2}{|c|}{2016} & \multicolumn{2}{|c|}{2017} & \multicolumn{2}{|c|}{$\begin{array}{l}2018 \text { Ocak- } \\
\text { Şubat }\end{array}$} \\
\hline & $\sum_{\mathscr{H}}$ & 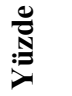 & 趈 & : & స్ర & 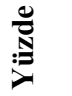 & $\sum_{\mathscr{N}}$ & 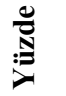 & 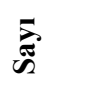 & 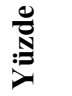 & $\sum_{\mathscr{D}}$ & 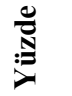 \\
\hline Elektrik Kontağı & 5133 & 18,0 & 5360 & 23,8 & 6564 & 24,3 & 6155 & 21,5 & 6.259 & 24,9 & 988 & 29,8 \\
\hline Sigara & 13010 & 45,6 & 9168 & 40,8 & 10532 & 39,0 & 11.34 & 39,6 & 8.420 & 33,5 & 938 & 28,3 \\
\hline $\begin{array}{l}\text { Kivılcım } \\
\text { Stçramast } \\
\end{array}$ & 967 & 3,39 & 903 & 4,02 & 1021 & 3,78 & 1122 & 3,92 & 1.178 & 4,70 & 261 & 7,88 \\
\hline Baca & 2097 & 7,35 & 749 & 3,33 & 1185 & 4,39 & 1093 & 3,82 & 1.100 & 4,39 & 232 & 7,01 \\
\hline Kasit & 1454 & 5,10 & 1340 & 5,97 & 2058 & 7,63 & 2729 & 9,55 & 1.981 & 7,90 & 209 & 6,31 \\
\hline $\begin{array}{l}\text { Ütü, Ocak (gazlı } \\
\text { dâhil) elektrikli } \\
\text { ev aletleri }\end{array}$ & 1190 & 4,17 & 1189 & 5,29 & 1245 & 4,61 & 1272 & 4,45 & 1.206 & 4,81 & 173 & 5,23 \\
\hline Diğer & 707 & 2,48 & 863 & 3,84 & 823 & 3,05 & 1276 & 4,46 & 1.014 & 4,04 & 161 & 4,86 \\
\hline $\begin{array}{l}\text { Kozısşma (yüksek } \\
\text { tsı ile) }\end{array}$ & 677 & 2,37 & 961 & 4,28 & 1107 & 4,10 & 842 & 2,95 & 943 & 3,76 & 130 & 3,93 \\
\hline Tespit Edilemedi & 762 & 2,67 & 830 & 3,69 & 956 & 3,54 & 1060 & 3,71 & 1.824 & 7,27 & 103 & 3,11 \\
\hline $\begin{array}{l}\text { Çocukların Ateşle } \\
\text { Oynamast }\end{array}$ & 2097 & 7,35 & 749 & 3,33 & 1159 & 4,30 & 1374 & 4,81 & 867 & 3,46 & 67 & 2,02 \\
\hline $\begin{array}{l}\text { Parlama (yantct } \\
\text { stvı parlamast } \\
\text { vb.) }\end{array}$ & 422 & 1,48 & 351 & 1,56 & 328 & 1,22 & 322 & 1,13 & 281 & 1,12 & 49 & 1,48 \\
\hline TOPLAM & 28516 & 100 & 22463 & 100 & 26978 & 100 & 28586 & 100 & 25073 & 100 & 3311 & 100 \\
\hline
\end{tabular}

Bu sınıflandırmanın içinde "diğer" ve "tespit edilemedi” başlıklarından artış olmasına izin verilmeyecek bir sistem kurulması gerektiği yadsınamaz bir gerçektir. Bu tür belirsizlik taşıyan veri türlerinde rakamsal olarak yığılmaların olması verilerin analizi ve değerlendirmelerde gerçek sonucu bulmamıza engel olacağ 1 için istenmeyen bir durum olarak göze çarpmaktadır. Bu bağlamda son 5 yıllık veriler incelendiğinde bu iki veri türünün (tespit edilemedi ve diğer) giderek arttığı görülmektedir. 2013 yılında 707 adet ve \%2,48'lik oranla toplam içinde yer alan “diğer” başlığı 2017 yılında 1014 adet ve \%4,04 oran ile neredeyse 2 kat artmıştır. Bunun anlamı 2017 yılında gerçekleşen 1014 adet olayın yangın çıkış nedeni Tablo 5'de yer alan sebeplerden hiçbiri değildir. Ancak bu nedenlerin dişında olup 1014 farklı neden olamayacağına göre sınıflandırmanın çeşitlendirme ihtiyacı olduğu sayısal değerler incelendiğinde çok net görülmektedir.

Benzer şekilde 2013 yılında 762 adet ve \%2,67'lik oranla toplam içinde yer alan "tespit edilemedi” başlı̆̆ 2017 yılında 1824 adet ve \%7,27'lik oran ile 3 kata yakın artmıştır. Belirsizliği artıran bu iki başlığın 2017 yılındaki toplamı 2828 adet ile toplam içinde \%8,8ile önemli bir yer tutmaktadır. Sistemli bir şekilde toplanan sayısal gerçekleri ifade eden istatistik, bir konu hakkında araştırma yapılmasını sağlamasının yanında ve sıkça sürekli iyileştirme çalışmalarında kullanılmaktadır. Bu sebeple verilerde belirsizliklerin olmaması gerçek nedenlere inilerek bu rakamların iyileştirme için kullanılması çok önem arz etmektedir.

Yangın istatistikleri; yangın sayıları, yangın çıkış sebepleri, yangınlarda meydana gelen can kayıpları ve yangınların sebep olduğu maddi zararlar acısından incelendiği bir çalışma sonunda, yangın sayılarının büyük oranda enerji tüketimi ve nüfus ile ilişkili olduğu görülmüş, yangınlara sebebiyet veren faktörlerin başında "sigara" ve "elektrik tesisatını" geldiği tablolarda gösterilmiştir. Sigara yasağından önce sigaradan kaynaklı yangınların sayısının fazla olduğu bu yasakla beraberinde bu oranda ciddi oranda artışlara rastlandığı belirtilmiştir. Türkiye'de ilk olarak yangın istatistikleri konusunda en detaylı çalışmaların İstanbul Büyükşehir Belediyesi tarafından veri ambarı projesi ile başladığı, oluşturulan bu veri tabanının tüm Türkiye'ye uyarlanması ve Türkiye genelinde yangın istatistikleri konusunda bir dil birliğinin oluşturulması gerektiği çalışmalarda belirtilmiştir (Bekem vd. 2011).

Dünyada yangın istatistikleri ile ilgili uzun yıllardır detaylı çalışmalar yapılmaktadır. Buna karşın ülkemizde yangın istatistiklerine ait resmi bir kurum tarafından yayınlanmış yönlendirici, bilgilendirici bir doküman bulunmamaktadır. Her ilde belediyesinde bulunan İtfaiye Daire Başkanlıkları veya İtfaiye Müdürlükleri tarafından yangın istatistikleri tutulmakta ve web sayfalarında yayınlanmaktadır (Bekem Kara 2017).

Artvin ili merkezinde meydana gelen bina yangınlarını inceleyen Bekem Kara (2018) çalışmasında itfaiye tarafından tutulan yıllık istatistiklerde yangınların mevsimlere, çıkış saatlerine, şehir merkezi ya da köylerde çıkması gibi özelliklere ait veri ve yangın olaylarında hayatını kaybeden veya yararlanan kişilere ait yaş ve cinsiyet gibi bilgileri de bulunmadığını vurgulamaktadir. 
Bekem Kara (2018)'e göre “Özellikle bina yangınlarında yangının çıkış noktası olan mahal oldukça önemlidir. Bu konuda da herhangi bir bilgiye rastlanmamıştır. Bu doğrultuda, tutulan yıllık istatistik cetvellerinin bahsedilen özellikler eklenerek İtfaiye Müdürlükleri tarafından güncellenmesi gerektiği düşünülmektedir”.

Yangın istatistiklerinin güvenilir, derinlikli bir sistem içinde tutulması ve yangın güvenliği stratejilerinin oluşturulması,

- Nitelikli insan kaynağı,

- Ülkemize özgü yangın güvenliği standartları,

- Yangin ekonomisi,

- Yangın güvenliği bilimi,

- Yangın güvenliği teknolojilerinin oluşturulması ve teknolojilerin etkin bir şekilde kullanılması,

- Yangin sigortacilığ

- Yangin hukuku (Ceza Hukuku, İdari Hukuku, ...),

gibi konularda gelişme ve değişim yaratacak, yeni teknik ve teknolojilerin ülkemizde kullanılabilir olması ve/veya geliştirilmesi temelli bakış ile insan kaynağımızın yangın güvenliğine özgü özellik ve nitelikler çerçevesinde eğitilmesini sağlayarak ülkemize özgü çözümler oluşturulmasını amaçlamalıdır.

\section{Yangın İstatistik Veri Türlerinin Türkiye ve Seçilmiş Ülkeler ile Karşılaştırılması}

Yangın istatistikleri ülkelere, yıllara, meydana gelme sebeplerine göre incelendiğinde insan kaynaklı yangınların daha fazla olduğu görülmektedir. Yangın istatistikleri ne kadar çok çeşitlilikte ve derinlikte olursa bu konuda kesin sonuçlar çıkartılabilmektedir. Bu bağlamda yangın güvenliği ve risk azaltma stratejileri için çeşitli veri türlerinden oluşan istatistikleri ve eğilimlerini incelemek gerekmektedir:

Yangın İstatistiklerinin amaca dönük kullanılabilmesi, yangın güvenliği stratejileri oluşturmak, yangın ekonomisi çerçevesinde etkinliğin incelenmesinde temel olarak kabul edilebilecek 43 başlık altında İstanbul özelinde Türkiye Yangın İstatistik verileri ile ABD, Çin, AB Ülkeleri, Kanada ve CTF Ülkeleri yangın istatistikleri karşılaştırılmıştır (Tablo 6). Bu çerçevede, 43 ana başlığın 15'i ülkemiz yangın istatistiklerinde tutulurken, bu sayının ABD'de 43, AB'de 11, Çin'de 12, Kanada'da 11 olduğu, CTIF istatistiklerinde ise bu sayının 19 olduğu görülmektedir. Fakat önemli olan istatistiklerin çeşitliliği değil bu çeşitliliğin stratejiye yansımasıdır.

Tablo 6'ya genel olarak bakıldığında, ABD'de tutulan yangın istatistiklerinin veri çeşitliliği açısından en kapsamlı verilere sahip olduğu görülmektedir. CTIF her yıl 70 ayrı ülkenin yangın istatistiklerini raporlayarak kümülatif yangın istatistiği oluşturmaktadır. Bu tutulan istatistiklerin ülkelerin büyük şehirlerindeki yangın eğilimlerini, yangınlar nedeniyle meydana gelen ölümleri, yaralanmaları, ülke itfaiye istatistikleri gibi hususları kapsadığı görülmektedir.

Yangın ekonomisi çalışmalarına yön verecek maliyet unsurlarını kapsayan veri türlerinin Tablo 6'da görüldüğü gibi genel olarak az olduğu, bunun dışında Türkiye'de itfaiyecilerle ilgili verilerin eksik olduğu kanısı ortaya çıkmıştır. Yangın ekonomisi açısından ülkelerin yangın güvenliği ve yangın kayıplarının incelenmesini sağlayacak veri çeşitliliğinin yeterince bulunmadığı göze çarpmaktadır. 
Tablo 6: Türkiye ve seçilmiş ülkelerle yangın istatistik veri türlerinin karşılaştırılması

\begin{tabular}{|c|c|c|c|c|c|c|}
\hline ISTATISTIKK TÜRLERİ & $T \ddot{U R K I Y Y E}$ & AMERIKKA & $A B$ & $C ̧ \dot{I N}$ & $K A N A D A$ & CTIF Ülkeleri \\
\hline Yangin Sayıst & $\mathrm{X}$ & $\mathrm{X}$ & $\mathrm{X}$ & $\mathrm{X}$ & $\mathrm{X}$ & $\mathrm{X}$ \\
\hline Yangın Türleri & $\mathrm{X}$ & $\mathrm{X}$ & $\mathrm{X}$ & $\mathrm{X}$ & $\mathrm{X}$ & $\mathrm{X}$ \\
\hline Yangının çıkma saati & $\mathrm{X}$ & $\mathrm{X}$ & $\mathrm{X}$ & $\mathrm{X}$ & $\mathrm{X}$ & \\
\hline Aylara göre yangınların dağılımı & $\mathrm{X}$ & $\mathrm{X}$ & & & & \\
\hline Ortalama Varış Süreleri & $\mathrm{X}$ & $\mathrm{X}$ & & & & \\
\hline $\begin{array}{r}\text { Yapısal Yangınlar(Konut, } \\
\text { Fabrika,...) }\end{array}$ & $\mathrm{X}$ & $\mathrm{X}$ & $\mathrm{X}$ & $\mathrm{X}$ & $\mathrm{X}$ & $\mathrm{X}$ \\
\hline Kazazedenin Yapıya Aşınalı̆̆ı & & $\mathrm{X}$ & & & & \\
\hline Yapısal Olmayan Yangınlar & $\mathrm{X}$ & $\mathrm{X}$ & $\mathrm{X}$ & & $\mathrm{X}$ & $\mathrm{X}$ \\
\hline Sivil Ölüm Sayısı & & $\mathrm{X}$ & & $\mathrm{X}$ & & $\mathrm{X}$ \\
\hline Sivil Yaralı Sayısı & & $\mathrm{X}$ & & $\mathrm{X}$ & & $\mathrm{X}$ \\
\hline $\begin{array}{r}\text { Yaralanmaya Sebep Olabilecek } \\
\text { Durumlar }\end{array}$ & & $\mathrm{X}$ & & & & \\
\hline İtfaiyeci Ölüm Sayısı & & $\mathrm{X}$ & & & & $\mathrm{X}$ \\
\hline Itfaiyeci Yaralı Sayısı & & $\mathrm{X}$ & & & & $\mathrm{X}$ \\
\hline Karayolu Taşıt Yangınları & $\mathrm{X}$ & $\mathrm{X}$ & $\mathrm{X}$ & & & $\mathrm{X}$ \\
\hline Maddi Kayıplar & & $\mathrm{X}$ & $\mathrm{X}$ & $\mathrm{X}$ & & \\
\hline Kasitlı Yangınlar & & $\mathrm{X}$ & $\mathrm{X}$ & & & \\
\hline $\begin{array}{r}\text { Diğer Araç Yangınları } \\
\text { (Uçak, tren, gemi, inşaat ve } \\
\text { tarım araçları) }\end{array}$ & & $X$ & $\mathrm{X}$ & & & \\
\hline Yanlış Yangın Alarm Sayısı & & $\mathrm{X}$ & & & & \\
\hline Itfaiyeci Sayısı & $\mathrm{X}$ & $\mathrm{X}$ & & $\mathrm{X}$ & $\mathrm{X}$ & $\mathrm{X}$ \\
\hline Gönüllü İtfaiyeci Sayısı & $\mathrm{X}$ & $\mathrm{X}$ & & $\mathrm{X}$ & $\mathrm{X}$ & $\mathrm{X}$ \\
\hline Sayının Cinsiyete Göre Dağılımı & & $\mathrm{X}$ & & & & $\mathrm{X}$ \\
\hline Itfaiye Departman Sayısı & $\mathrm{X}$ & $\mathrm{X}$ & & $\mathrm{X}$ & $\mathrm{X}$ & $\mathrm{X}$ \\
\hline İstasyonların Yaşı ve Yeterliliği & & $\mathrm{X}$ & & & & \\
\hline Ittaiye Acil Sağllk Hizmeti & $\mathrm{X}$ & $\mathrm{X}$ & & & $\mathrm{X}$ & $\mathrm{X}$ \\
\hline $\begin{array}{r}\text { itfaiye Aparatlar } \\
\text { (cihaz, alet, malzeme, ...) }\end{array}$ & $\mathrm{X}$ & $\mathrm{X}$ & & $\mathrm{X}$ & $\mathrm{X}$ & $\mathrm{X}$ \\
\hline $\begin{array}{r}\text { Kişinin Yangın öncesi - sonrasi } \\
\text { psikolojik durumu }\end{array}$ & & $\bar{X}$ & & & & \\
\hline $\begin{array}{r}\text { Farkındalık Çalışmaları ve } \\
\text { Eğitimler }\end{array}$ & $\mathrm{X}$ & $\mathrm{X}$ & & & & \\
\hline $\begin{array}{r}\text { Eğitime İhtiyaç Duyulan } \\
\text { Bölümlerin Tesbiti }\end{array}$ & & $\mathrm{X}$ & & & & \\
\hline Hibe Fonlart & & $\mathrm{X}$ & & & & \\
\hline Tehlikeli Madde & & $\mathrm{X}$ & $\mathrm{X}$ & & & \\
\hline $\begin{array}{r}\text { İleri Teknoloji Yaklassımlarını } \\
\text { Kullanma }\end{array}$ & & $\mathrm{X}$ & & & & \\
\hline $\begin{array}{l}\text { Itfaiyeci için Temel Fitness ve } \\
\text { Sağlığını Koruma Programı }\end{array}$ & & $\mathrm{X}$ & & & & \\
\hline Kişisel Koruyисu Ekipman & & $\mathrm{X}$ & & & & \\
\hline Yangın Önleme Çalıșmaları & & $\mathrm{X}$ & & & & \\
\hline Toplam Yangın Aramalart & & $\mathrm{X}$ & & & & $\mathrm{X}$ \\
\hline Ambulans için Aramalar & & $\mathrm{X}$ & & & & $\mathrm{X}$ \\
\hline Yanlış - Cevapsız Aramalar & & $\mathrm{X}$ & & & & $\mathrm{X}$ \\
\hline Kod Zorlamast & $\mathrm{X}$ & $\mathrm{X}$ & $\mathrm{X}$ & $\mathrm{X}$ & $\mathrm{X}$ & $\mathrm{X}$ \\
\hline $\begin{array}{l}\text { Olağandışı zorlu olayların } \\
\text { üstesinden gelme yeteneği }\end{array}$ & & $\mathrm{X}$ & & & & \\
\hline Ek tesis ihtiyaç analizleri & & $\mathrm{X}$ & & & & \\
\hline Yapısal Yangınla Mücadele & & $\mathrm{X}$ & & & & \\
\hline Yapısal Çöküş Kurtarma Ekibi & & $\mathrm{X}$ & & & & \\
\hline $\begin{array}{r}\text { Yangın Alanı Hava Kalitesi } \\
\text { Çalışmaları, Gaz, Türleri Oranı }\end{array}$ & & $\mathrm{X}$ & & & & \\
\hline
\end{tabular}

\section{Sonuç ve Tartışma}

Strateji belirlemek için veri toplama, analizi, strateji oluşturma ve strateji seçimi (Ülgen ve Mirze 2004) yapılması gerekmektedir. $\mathrm{Bu}$ süreçte strateji oluşturmanın başlangıcı veri toplamaktır. Bu sebeple istatistik, strateji belirlemede önemli bir yer tutmaktadır. Çalışmada, yangınla ilgili stratejiler belirlemek için kullanılmış olan yangın istatistiklerindeki verilerin çeşitliliği, Türkiye için İstanbul ili özelinde ve seçilmiş ülkelerle karşılaştırılmıştır. 
Türkiye'de sadece tutulan ya da yayınlanan verilerde yangın çıkış nedenleri, aylara ve saatlere göre ne sıklıkta yangın çıktığı varsayımlarına ulaşılabilmesine rağmen insan yaralanma ve/veya kayıplarına ki TÜİK tarafından yayınlanan ölüm istatistiklerinde ölüm nedenlerinde yangından ölümlere yer verilmediği gözlemlenmiştir. Diğer ülkelerde yangın istatistikleri ile GSYİH değerlerinin bile değerlendirildiği, yangın ölümleri ve trafik kaynaklı ölümlerin karşılaştırılıp belli metodojilerle araştırmalar yapıldığına rastlanmıştır.

İstanbul ili verileri ile ABD, Çin ve $\mathrm{AB}$ ülkelerinde tutulan yangın istatistik veri türleri karşılaştırıldığında ülkemizde tutulan yangın istatistiklerinin yeterli olmadı̆̆ı gözlemlenmiştir.

Sonuç olarak Türkiye'de yangınların azaltılması, toplumda bilinçlendirmenin yapılması, farkındalık sağlanması gibi birçok stratejilerin belirlenmesine ve bu konuda hedeflerin gerçekçi oluşturulmasına yardımcı olacak analitik yaklaşım için istatistiklerin önemi büyüktür. Bu bağlamda veri çeşitliliğinin artırılması gerekmektedir. "Diğer" ve "tespit edilemedi” gibi belirsizlik taşıyan veri türlerindeki artış, veri çeşitliği ile verilerin gerçekçi analiz ve değerlendirilmesin önünde engel oluşturacaktır. Belirsizliği artıran veri türlerinin artışına izin vermeyen bir sistem kurulmalıdır. Kritik olan can kayıpları ve yaralanmalar (ki tüm detaylarıyla istatistiklerde yer almalı)maliyetlerle ilgili verilerin strateji belirlemede büyük önemi olduğu söylenebilir.

\section{Kaynaklar}

Bekem İ., Çavuş M., Demirel F., (2011), Türkiye Ölçeğinde Yangın İstatistikleri Üzerine Bir Araştırma, Tüyak 2011, Yangın ve Güvenlik Sempozyumu ve Sergisi, İstanbul.

Bekem Kara İ., (2017), Investigation of Giresun fire statistics (2011-2016), The Black Sea Journal of Sciences, 7(2), 96-105.

Bekem Kara İ., (2018), 2013-2017 Yilları Arasinda Artvin İl Merkezinde Meydana Gelen Bina Yanginlarinin İncelenmesi, Doğal Afetler ve Çevre Dergisi, 4(2), 105-114.

Brushlinsky N., Ahrens M., Sokolov S.V., Wagner P., (2017), Center of Fire Statistics of CTIF, https://www.ctif.org/commissionsand-groups/ctif-center-fire-statistics, [Erişim 31 Mart 2018].

Camia A., Durrant T., San-Miguel-Ayanz J., (2013), Harmonized classification scheme of fire causes in the EU adopted for the European Fire Database of EFFIS, http://publications.jrc.ec.europa.eu/repository/bitstream/JRC80682/lb-na-25-923-en-n.pdf, [Erişim 31 Mart 2018].

Çil B., (2008), İstatistik, Detay Yayıncılık, Ankara, ss.408.

Dilek M., (1999), İstatistik, Muğla Üniversitesi Basımevi, Muğla, ss.48.

FEMA, (2015), National Fire Incident. U.S. Fire Administration, https://www.usfa.fema.gov/downloads/pdf/nfirs/NFIRS_Complete_ Reference_Guide_2015. pdf, [Erişim 31 Mart 2018].

GAIN, (2009), World Fire Statistics, Information Bulletin of the World Fire Statistics Centre, Geneva Association Information Newsletter.

Ramachandran G., (1998), The Economics of Fire, London and New York: Published by E \& FN Spon.

Haynes H.J., (2017), Fire Loss in the United States During 2016, https://www.maine.gov/dps/fmo/research/documents/nfpa _ firelossinus_2016.pdf, [Erişim 31 Mart 2018].

İBB İtfaiye Daire Başkanlığı, (2018), İstatistikler, İstanbul İtfaiyesi, http://itfaiye.ibb.gov.tr/img/144238852018_9950067400.pdf, [Erişim 31 Mart 2018].

Kobayashi M., (1984), Urban Post-Earthquake Fires in Japan, Proceedings of the Eighth World Conference on Earthquake Engineering, Prentice-Hall, Inc., Englewood Cliffs, New Jersey, Copyright with the Earthquake Engineering Research Inst., El Cerrito, California, Vol. VII, 785-792.

Koraltürk G., (2000), Deprem Sonrası Yangınlar ve Modellenmesi, Yüksek Lisans Tezi, İstanbu Teknik Üniversitesi, Fen Bilimleri Enstitüsü, İstanbul.

Özkan Y., (2002), Uygulamalı İstatistik I, Sakarya Kitabevi, Sakarya, ss.395.

Şanslı Ş., (2008), Tamamlayıcı İstatistik, Nobel Yayın Dağıtım, Ankara, ss.326.

Ülgen H., Mirze S.K., (2004), İşletmelerde Stratejik Yönetim, Literatür Yayınları No:11, İstanbul, ss.702.

Üstündağ Ö., Boyraz Z., (2008), CBS Yardımı İle Kent İ̧̧i Yangın Analizi: Elazığ Örneği, New World Sciences Academy, 3(2), $307-$ 320.

Wang F., Lu S., Li A.C., (2005), Analysis of Fire Statistics of China: Fire Frequency, Fire Safety Science-Proceedings of the Eighth International Symposium, 353-362, https://www.iafss.org/publications/fss/8/353/view/fss_8-353.pdf, [Erişim 31 Mart 2018 ]. 